\title{
Acute morning glory syndrome: report of a case
}

\author{
K. RUBINSTEIN
}

From the Birmingham and Midland Eye Hospital

SUMMARY In 1976 a boy of 12 presented with unilateral morning glory syndrome connected with oedema of the posterior fundus and marked loss of vision. The recovery was complete within a few months, with visual acuity improving to $6 / 4$. The other eye could see $6 / 4$ and had a normal fundus throughout.

A 12-year-old boy was seen in February 1976 complaining of blurred vision in the right eye for the previous 2 weeks. His visual acuity was $6 / 12$ in this eye and $6 / 4$ in the left eye. The fundus of the right eye showed diffuse oedema of the posterior pole with hazy outline of the optic disc and marked oedema of the macula. Small streaky exudates were sprinkled all round the periphery of the oedematous area, which was centred on the optic disc (Fig. 1).

During the following week the vision fell to $6 / 18$ and a strikingly large macular star could be seen at the

Correspondence to $\mathrm{Mr} \mathrm{K}$. Rubinstein, 10 Pritchatts Road, Edgbaston, Birmingham B15 2QT.

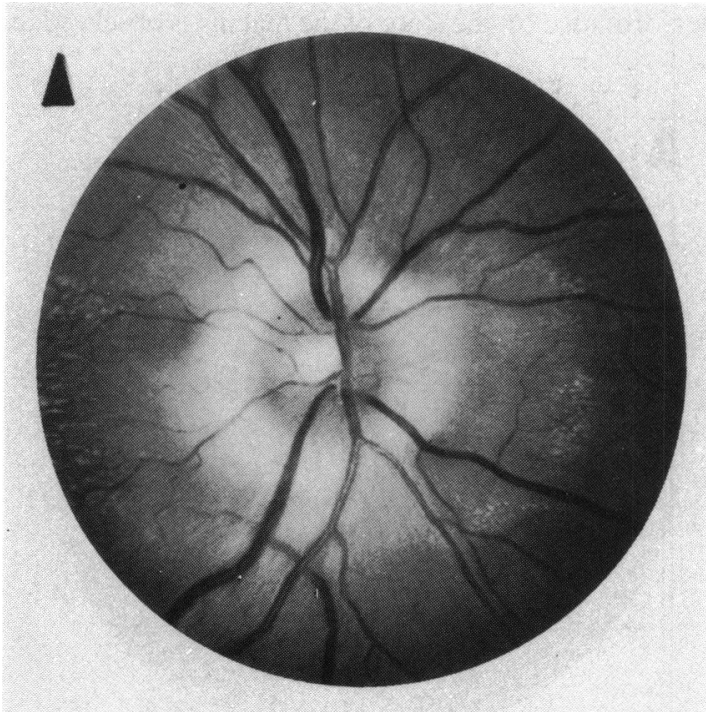

Fig. 1A Right fundus. Red-free photograph 2 weeks after onset of symptoms. Vision 6/12. Generalised oedema of the optic disc and all posterior fundus. Early fine sprinkling of striate exudates round the disc. macula. Within a week vision improved to 6/12. From then on one could observe a gradual disintegration of the star and regression of posterior pole oedema. The optic disc could now be outlined; it looked lumpy, swollen, and hazy (Fig. 2).

Four weeks later vision improved to $6 / 5$. The optic disc showed clearly a morning glory picture with a sharp central white blob and oedema of the tyreshaped annulus. Four months after the onset visual acuity was $6 / 4$. The optic disc oedema had gone but the macular star took another 2 months to resolve.

Since then the patient has been followed up for 6 years without any further changes either in vision or

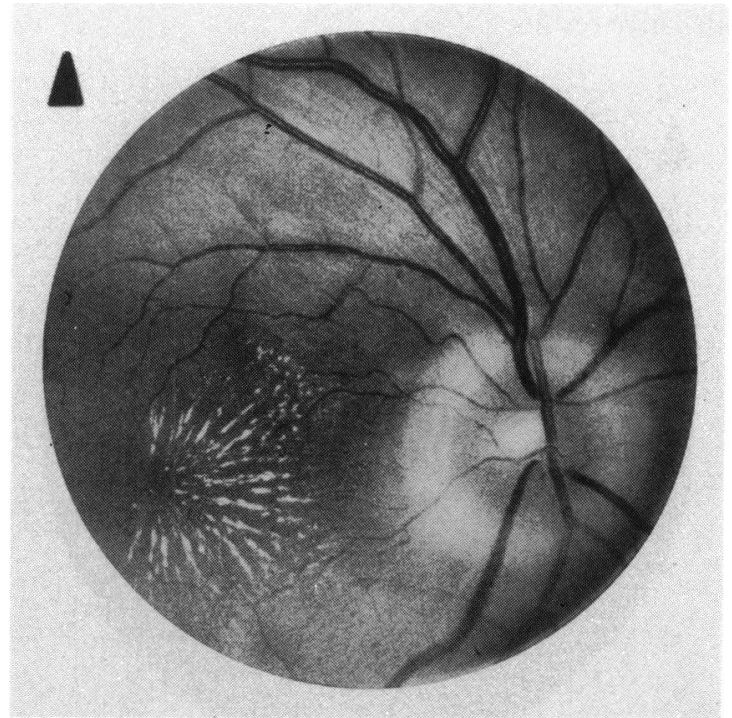

Fig. 1B One week later. Red-free photograph. Vision 6/18. Exudates form now a complete macular star. The disc area is still diffusely oedematous. 


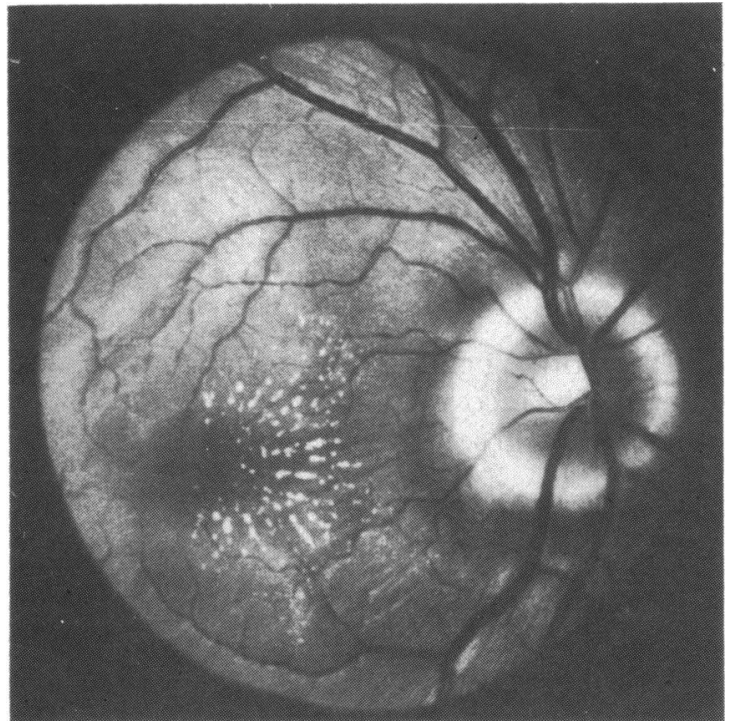

Fig. 1C Red-free photograph. Six weeks after the onset of symptoms visual acuity 6/12. The macular star is breaking and absorbing. The disc is surrounded by tyre-shape white ring, which is swollen. At the bottom of a central disc excavation there is a white blob. Visual acuity $6 / 6$.

in the appearance of the fundi. During the last 2 years some increase in granular black pigmentation of the annulus was noticed. The left fundus remained unchanged during the whole episode, and apart from some nasalwards crowding of retinal vessels it showed no abnormality (Fig. 3). Systemic investigations gave negative results.

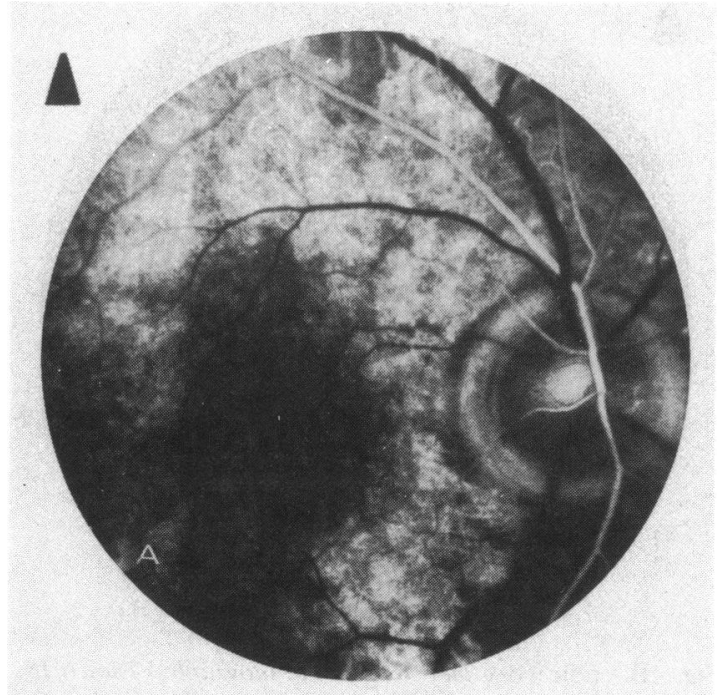

\section{Discussion}

This peculiar congenital anomaly of the optic disc was first reported by Handmann. ${ }^{1}$ Other reports followed, ${ }^{2-4}$ including that of Kindler, ${ }^{5}$ who christened the anomaly 'morning glory' because of its similarity to flowers in the genus Ipomoea, which are similar to those of the convolvulus of British hedgerows. The presence of a shallow posterior retinal detachment without holes was observed in 5 of them. In Kindler's case 4 this was accompanied by a haemorrhage at the edge of the malformed optic disc, but it eventually absorbed. Other cases were described in which morning glory discs were a part of gross ocular and neurological congenital abnormalities, e.g. basal encephalocoele, ${ }^{6}$ coloboma of the choroid, ${ }^{7}$ microphthalmos, ${ }^{8}$ and persistent hyperplastic primary vitreous. ${ }^{89}$

The posterior pole oedema seen in our case could be designated a serous retinal detachment. It was superficial; the serum cleavage was located in the nerve fibre layer, and there were no signs of uveal effusions. The hard exudates forming the macular star took several months to absorb, but the initial impairment of vision and its recovery seemed to depend entirely on the state of the macula and not on the state of the optic disc. As regards the oedema of the disc, the initial flush of marked effusion shown on fluorescein angiography was followed by permanent hyperfluorescence of the disc tissues alone after 6 years of observation.

It is interesting that a similar dependence of visual performance on the state of the macula is observed in

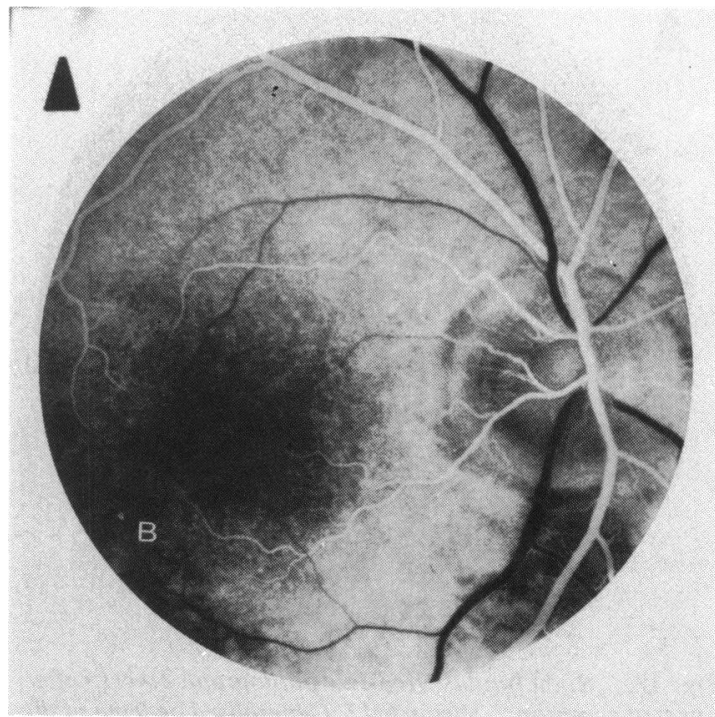

Fig. 2 Fluorescein angiography. Four months after the onset of symptoms. A: Choroidal stage. Note the prompt fluorescence of central blob and some fluorescence from the peripapillary annulus. B: Note the fading of the central blob. 


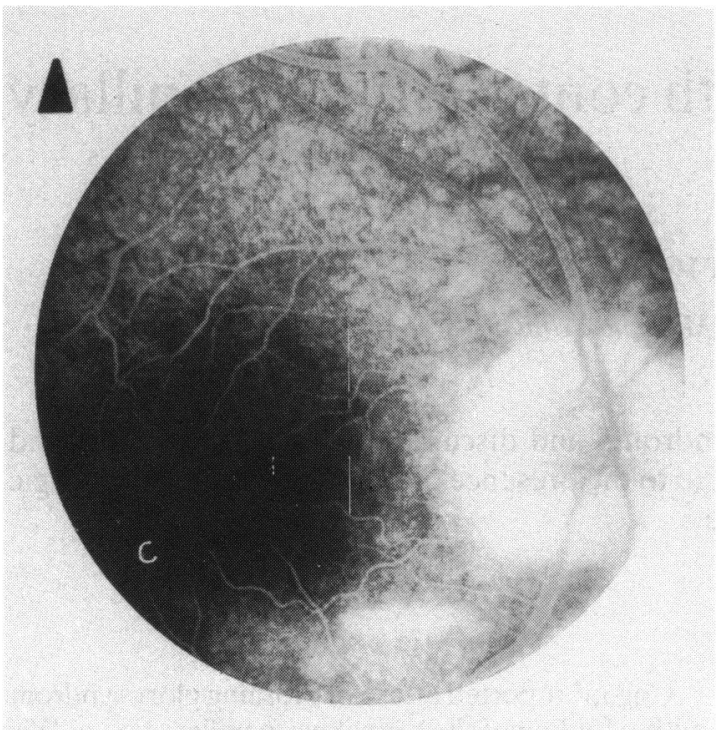

Fig. 2C 30-seconds stage: fluorescein effusion from the disc.

other congenital anomalies of the disc: optic disc pits $^{10}$ and coloboma, optic disc drusen, ${ }^{11}$ and posterior hyperplastic primary vitreous. It is also interesting that these congenital anomalies may not be static but can cause visual symptoms and changes in the fundus appearance well into adult life.

\section{References}

1 Handman M. Erbliche, vermütlich angeborene zentrale gliose Entartung des Sehnerven mit besonderer Beteilugung der Zentralgefässe, Klin Monatsbl Augenheilkd 1929; 83: 145-52.

2 Badtke G. Über de grossenanomalien der Papilla nervi optici, unter besonderef Berucksichtigung der schwarzen Megalopapille. Klin Monatsbl Augenheilkd 1959; 135: 502-10.

3 Krause U. Three cases of the morning glory syndrome. Acta Ophthalmol (Kbh) 1972; 50: 188-98.

4 Jensen PE, Kalina RE. Congenital disk anomalies. Am J Ophthalmol 1982; 82: 27-31.

5 Kindler P. Morning glory syndrome: unusual congenital optic disk anomaly. Am J Ophthalmol 1970; 69: 376-84.

6 Goldhammer Y, Smith JL. Optic nerve anomalies in basal encephalocele. Arch Ophthalmol 1975; 93: 115-8.

7 Jesberg DO, Schepens CL. Retinal detachment associated with coloboma of the choroid. Arch Ophthalmol 1961; 65: 163-73.

8 Hamada S, Ellsworth RM. Congenital retinal detachment and the optic disc anomaly. Am J Ophthalmol 1971; 71: 460-4.

9 Gass JDM. Surgical excision of persistent hyperplastic primary vitreous. Arch Ophthalmol 1970; 83: 163-8.

10 Rubinstein K, Ali M. Complications of optic disc pits Trans Ophthalmol Soc UK 1978; 98: 195-200.

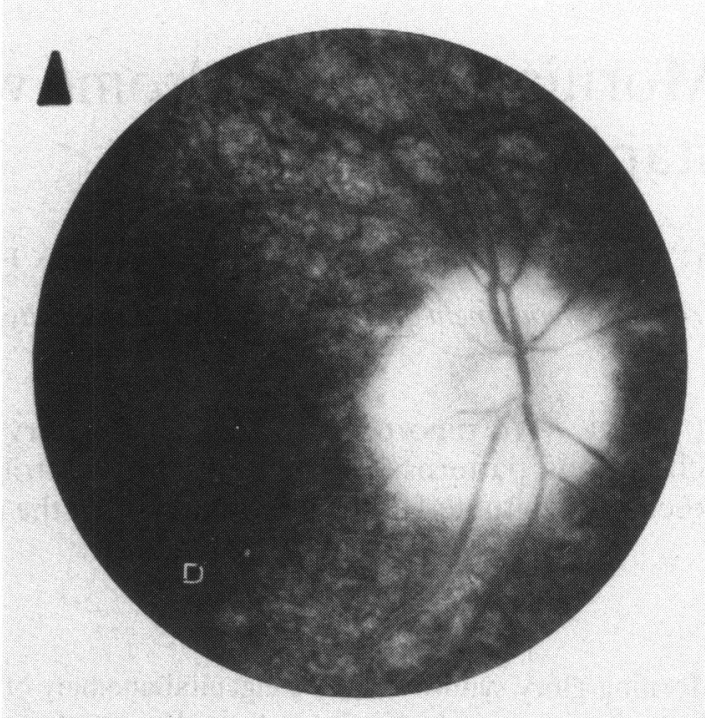

Fig. 2D 2 minutes stage: limited fluorescence of the disc mainly from the annulus.

11 Rubinstein K, Ali M. Retinal complications of optic disc drusen. Br J Ophthalmol 1982; 66: 83-95.

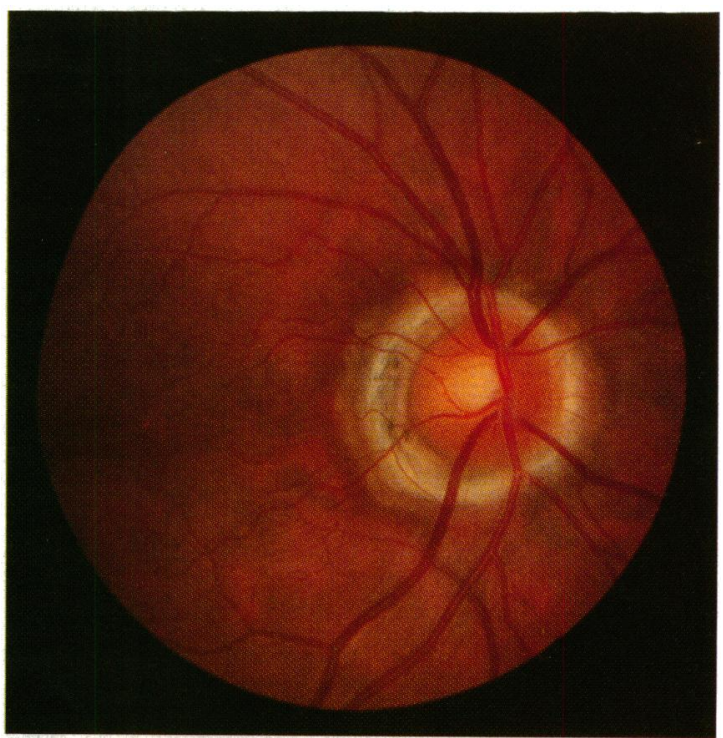

Fig. 3 The fundus 1 year later and unchanged for the following 6 years of observation apart from some increase of granular pigmentation of the annulus. Visual acuity 6/4. No symptoms. 